Federal Reserve Bank of Minneapolis

Research Department

\title{
Analyzing a Proposal to Ban State Tax Breaks to Businesses
}

Thomas J. Holmes*

Working Paper 544

Revised May 1995

*Federal Reserve Bank of Minneapolis. This paper is fortheoming in the Federal Reserve Bank of Minneapolis Quarterly Review. The views expressed herein are those of the author and not necessarily those of the Federal Reserve Bank of Minneapolis or the Federal Reserve System. 


\section{Analyzing a Proposal to Ban State Tax Breaks to Businesses}

Thomas J. Holmes*

Economist

Research Department

Federal Reserve Bank of Minneapolis

$\$ 150$ million from South Carolina to BMW, $\$ 200$ mitlion from Utah to Micron Technology, $\$ 240$ million from Illinois to Sears, Roebuck, . . . The list is long and includes most states and most major industries in the United States (Schweke, Rist, and Dabson 1994, pp. 14, 15, 27; Zipser 1995, p. 24). State governments now regularly offer large tax breaks to specific private businesses in order to attract them to their states or keep them there.

But this common type of tax discrimination has recently been criticized strongly. Earlier this year, for example, the Wall Street Journal criticized the governor of Michigan for proposing a new state agency that would have the express purpose of doling out tax breaks to attract businesses (Review and outlook, 1995). And in an essay in the 1994 annual report of the Federal Reserve Bank of Minneapolis, Burstein and Rolnick (1995) criticized the general practice of states offering preferential tax treatment to particular businesses. Burstein and Rolnick went further than the Wall Street Journal by proposing that the federal government actually do something about this practice-specifically, that Congress pass a law prohibiting it.

How can economists justify a ban against state tax breaks for particular businesses? If we think that state officials are ignorant about what is best for their 
state, then we could justify such a ban in the same way that federal action to make people wear seat belts is justified-to save people from the consequences of their ignorant impulses. But if we assume that state officials actually do behave so as to maximize some measure of welfare of the residents of their state, then could a federal law that interferes with the ability of state officials to set state policies actually raise the overall welfare of U.S. residents?

I think so, and the purpose of this article is to demonstrate why. Here I consider a formal model in which officials of state governments act rationally to maximize the welfare of their residents. The analysis compares a regime in which state governments can legally offer discriminatory tax breaks to particular businesses (the status quo) with another regime in which such tax breaks are illegal (the Burstein-Rolnick policy). The analysis shows that making tax breaks illegal can increase a summary measure of total welfare in the economy. The policy can lead to a more efficient pattern of industry location and can increase the level of public good spending.

State government officials, when criticized for their discriminatory tax policies, often argue that they have no choice but to offer tax breaks because other states offer them. According to the Wall Street Journal, for example, the governor of Michigan claimed that not to create the state agency described above would mean that 'Michigan would 'unilaterally disarm' before the 44 other states that offer some form of tax sweeteners" (Review and outlook, 1995). The governor's point is valid in the context of my model. Practicing tax discrimination is always rational for an individual state. Yet, as my analysis shows, this narrow view misses a broader point: 
the states altogether would be better off under a federal policy that prevents them from tax-discriminating.

To understand this seeming contradiction, consider the arms race between the United States and the former Soviet Union. Stockpiling arms is individually rational for each side in this competition, regardless of what the other side does. If the Soviets have a buildup of arms, the United States is better off also building up arms, in order to neutralize a Soviet advantage. If the Soviets do not have a buildup, then building up is still rational for the United States, in order to take an advantage. The equilibrium outcome is for both sides to stockpile arms. Yet both sides would prefer a world in which neither stockpiles arms. Hence the welfare of both sides could be enhanced if somehow the option of stockpiling arms could be taken away from them both. In the same way, states can be better off if a federal law takes away the option of offering tax breaks to particular businesses.

Many state government officials well recognize that they might gain by cooperating rather than competing for one another's businesses. In fact, some states have attempted to form nonaggression pacts. In 1991, for example, New York, Connecticut, and New Jersey agreed not to compete for one another's businesses (though the agreement soon broke down). (See Burstein and Rolnick 1995, pp. 10-11.) Here I do not try to make the point that states might gain from cooperation, for this point is already widely understood. ${ }^{1}$ Rather, I try to make the point that states might gain if a federal law were to change the dimensions under which states compete. In both regimes that $I$ consider, states act noncooperatively; that is, they act so as to maximize the welfare of the residents within their own states as opposed to the interests of the country as a whole. In the Burstein-RoInick regime, in which tax 
breaks are illegal, state governments compete to attract capital just as they do in the status quo regime, in which tax breaks are legal. The difference is that in the Burstein-Rolnick regime, when a state government offers a low tax rate in order to attract capital, it must offer the same low rate to all businesses that locate within the state and not discriminate by offering the low rate to just a few.

In this analysis, the Burstein-Rolnick policy can affect aggregate welfare in two ways. One is to eliminate distortions in the location of businesses that are caused by the incentive to take advantage of special tax breaks. Without the policy, this type of state competition for businesses could result in anomalous situations like a banana plantation in Alaska. That sort of situation doesn't happen with the Burstein-Rolnick policy.

The other way the policy can affect welfare is to reduce the deadweight loss caused by taxation. The policy accomplishes this by making the tax burden more equal. Doing that affects not just the distribution of the social pie; it also affects the size of the pie. In general, taxes create a deadweight efficiency loss, and the size of the deadweight loss increases disproportionately with the amount of tax revenue collected from agents. To the extent that agents in the economy are similar in the way that their income-producing activities respond to tax rates, the deadweight loss of collecting a given amount of total tax revenue is minimized by spreading the burden evenly. Hence, to the extent that the Burstein-Rolnick policy makes the tax burden more equal across agents, it can increase the size of the social pie. By doing this, the Burstein-Rolnick policy can also lead to increased funding for public goods. A more equal distribution of a given tax burden reduces the marginal social cost (including 
any deadweight loss) of collecting another dollar of tax revenue. This reduction in marginal cost induces policymakers to increase spending on public goods.

My analysis connects two previously unrelated strands of literature. One is a public finance literature on tax competition between local jurisdictions. (See, for example, Wilson 1986 and Wildasin 1991.) In this literature, local governments want to attract capital because taxes on capital help pay the bills. Governments are modeled as playing a noncooperative game in the competition for capital. This literature does not consider what happens when local governments can offer different taxes to different capital units; that is, it does not consider tax discrimination.

The other strand of literature is an industrial organization literature on price discrimination by oligopolistic firms. (See, for example, Holmes 1989 and Borenstein 1985.) This literature compares a regime in which firms can price-discriminate with a regime in which they cannot; the firms must offer a uniform price to all markets. One of the results in Holmes 1989 is that the profit of oligopolistic firms can be higher in the regime in which price discrimination is illegal. A similar thing happens here. The equilibrium amount of tax revenue collected from capital is higher in the regime in which tax discrimination is illegal.

Formal analyses of government policy rarely produce unambiguous results that a particular policy is better than another under all circumstances. This analysis is no exception. In the basic model I consider, adoption of the Burstein-Rolnick policy does improve welfare over the entire range of possible parameters. Nevertheless, as I discuss, other models can be constructed in which adoption of this policy can actually reduce both the equilibrium tax revenue from capital and overall welfare. This means one must be very cautious in interpreting my results. The main message 
of the article is that a reasonable economic analysis concludes that all states could be better off with a federal law that prevents state officials from offering discriminatory tax breaks. But whether or not the conditions under which this result is obtained are empirically true is something that still needs to be examined.

\section{A Model}

Let's start the analysis with a general description of the model I will use.

\section{An Overview}

My model has two locations that I call states. It also has two kinds of agents, labor agents and capital agents. Labor agents are immobile; they are stuck in a particular state. Capital agents are identical to labor agents except that capital agents have some degree of mobility between the two states. Each state has a local public good that must be financed by taxes on labor and capital. The labor agents and capital agents both value the public good. Each state has a government that has the objective of maximizing the utility of the labor agents in the state. Each government would like to attract more capital agents to its state because this would increase the number of agents over which to spread the cost of the public good; that would decrease the cost to each labor agent and so increase individual utility. Each state competes for capital agents by making an offer of a tax rate and public good level that an agent would face if he or she were to locate in the state.

My model of tax competition is similar in spirit to models in the public finance literature, but it is different in many of the particulars. A representative public finance model is that of Wildasin (1991). In his model, capital agents do not value the public good while in my model they do. My assumption captures the 
plausible idea that capital agents care not only about the taxes they must pay, but also about the public services they can get for their money. Another feature of the Wildasin model is that the public good is completely financed by taxes on capital. In competition for capital, a government cannot commit to both a tax rate and a public good level since the government has no way to guarantee that its budget will balance. Wildasin studies one model in which the tax rate is the government's strategic variable and another model in which the public good level is its strategic variable. In my model, a government has as its strategic variables both a tax level and a public good level. Taxes on the immobile agents ensure that a government can balance its budget.

\section{A Closer Look}

Now let's look at the details of the model.

The economy of my model has three goods: a private consumption good, a public consumption good, and leisure. The quantities of the private good, the public good, and leisure consumed by an individual are denoted $x, y$, and $l$. All individuals in the economy have identical preferences, and these are represented by the additively separable utility function

$$
v(x, y, l)=x+u(y)+g(l)
$$

where $u(y)$ is the part of utility that arises from consumption of the public good and $g(l)$ is the part that arises from consumption of leisure. Both functions $u$ and $g$ are strictly increasing and strictly concave.

Each individual is endowed with one unit of time. This time can be allocated to production of the private consumption good or to leisure. One unit of time 
produces one unit of the private consumption good. Production of the private good has constant returns to scale (so one-half a unit of time produces one-half a unit of the private good).

The public good is produced using the private good as input. One unit of the private good can be converted into one unit of the public good.

The economy has two locations, denoted state 1 and state 2 . It has a continuum of individuals, and the measure of the total population is $2 N$. Individuals can be classified into two groups, the labor group and the capital group. The distinction between these two here is that all labor agents are completely immobile while capital agents are not; they have some degree of mobility. In no sense are labor and capital different inputs in a production function. I could have called the labor agents immobile agents and the capital agents mobile agents. I used the labor/capital terminology instead because capital is the mobile input over which states compete in the literature and in policy discussions.

Each labor agent in the model is exogenously stuck in a particular state. The measure of labor agents stuck in state 1 is $\alpha N$, and the measure stuck in state 2 is $\alpha N$. (Hence $\alpha \leq 1$ is the labor agent share of the total agent population.)

Capital agents can locate in either state. These agents may have a preference for one state or the other. That is, they are imperfectly mobile. Location preferences are modeled as follows. Each capital agent has a location preference type $s \in$ $[-\lambda, \lambda]$, where $\lambda$ is a parameter indicating the range of $s$. A capital agent with $s>$ 0 prefers state 1 over state 2 if all other conditions are the same. If this agent locates in state 1 , then his or her utility for the commodity vector $(x, y, l)$ is given by equation (1) for $v(x, y, l)$. But if this agent locates in state 2 , then his or her utility is given by 
$v(x, y, l)-s$. Hence the variable $s$ represents the capital agent's disutility (in terms of the private good $x$ ) suffered when the agent lives in his or her less-preferred location. The case of a capital agent with $s<0$ is analogous. Such an agent prefers state 2 over state 1 . If the agent lives in state 2 , then the agent's utility is $v(x, y, l)$, but if the agent lives in state 1 , it is $v(x, y, l)-|s|$. In summary, a capital agent prefers to live in state 1 if the agent's type $s$ is positive and prefers state 2 if it is negative. The disutility from living in the less-preferred state is given by the absolute value $|s|$. It can also be thought of as the cost to a capital agent of switching from one state to another.

Let $F(s)$ be the distribution of $s$ among the capital agents, and let $f(s)$ be the density function of $s$. This density function is symmetric around $s=0$. In particular, $f(s)=f(-s)$, and $F(0)=1 / 2$. Thus, half the capital agents prefer state 1 , and half prefer state 2. Furthermore, the distribution of the disutility $|s|$ is the same for those who prefer state 1 as for those who prefer state 2 .

The fact that the economy has two states is significant because the public good is local. That is, there will be a certain amount $y_{1}$ of state 1's public good and a certain amount $y_{2}$ of state 2's public good, and an agent's utility from the public good depends only on the amount that is locally provided. In other words, if an agent lives in state 1 , then his or her utility from public good consumption is $u\left(y_{1}\right)$, which is independent of the level of the public good $y_{2}$ provided in state 2 .

In each state, the public good is financed by taxation that is proportional to the amount of the private good that an agent produces. Each agent faces some tax rate $t$ on private good production. If the agent produces $x$ units of the private good, then the local government collects $t x$ units of that good in taxes, and the agent gets 
to keep the rest, $(1-t) x$ units. The proportional taxation of private good production introduces an inefficiency because it obviously distorts the margin between consumption of leisure and production of the private good (because leisure is not taxed). The assumption that taxation leads to a distortion is critical for this analysis. If lump-sum taxation were assumed instead, the distortion would disappear and so would some of the effects identified.

All that remains to be described in my model is how governments behave. The goal of the government in state 1 is to maximize the welfare of the labor agents in state 1 , and the goal of the government in state 2 is to maximize the welfare of the labor agents in state 2 . The government in each state has no direct interest in the welfare of capital agents. However, indirectly each government cares about the welfare of capital agents because the higher the welfare of capital agents in a state, the more capital agents will be attracted to it. (This is good for labor agents because it expands the tax base and cuts their taxes.)

Before equilibrium in this economy is defined, note that the economy has a nonconvexity. The consumption of the public good is nonrivalrous. Therefore, if the population of a state were doubled, then the cost per person of funding a given level of the public good $y$ would be cut in half. Suppose that all agents were capital agents, so that all agents were mobile. (This is the limiting case of $\alpha=0$.) Suppose further that the mean switching cost $|s|$ were relatively low, so that the two locations were close substitutes. Given the increasing returns, the socially efficient allocation in this case clearly would be for the entire population of capital agents to locate in one state and to leave the other state empty. In the analysis, I will assume that $\alpha$ is relatively high, so that labor agents constitute a relatively large share of the population. 
Therefore, regardless of what happens to the capital agents, population is spread out across the two locations, at least to some degree. Since the capital agents have a preference for one state or the other, the forces at work in the model to have capital agents locate all in one place are diminished. As will be discussed, for some parameters of the economy, the unique equilibrium allocation has the capital agents evenly split between the two locations. My focus is on such symmetric equilibria.

\section{Two Regimes}

Now I will describe the two taxation regimes that I want to compare: the status quo, or the discriminatory taxation regime, in which states can offer different tax rates to different capital agents, and the uniform taxation regime, proposed by Burstein and Rolnick, in which states cannot legally discriminate in this way.

\section{The Proposal: Uniform Taxation}

I will start with the uniform taxation regime because it is simpler than the discriminatory taxation regime.

\section{The Game}

As is common in such analyses, the interaction among the agents and the governments is modeled as a game. Here the game has three stages. In the first stage, the government of each state $i$ makes an offer of a level of public good provision $y_{i}$ and a tax rate $t_{i}^{c}$ that a capital agent will face if the agent locates in state $i$. Government behavior is Nash here. That is, state 1 takes $y_{2}$ and $t_{2}^{c}$ as given when it chooses $y_{1}$ and $t_{1}^{c}$, and state 2 takes $y_{1}$ and $t_{1}^{c}$ as given when it choose $y_{2}$ and $t_{2}^{c}$. 
In the second stage of the game, each capital agent examines the package $\left(y_{i}, t_{i}^{C}\right)$ offered at each location and chooses to locate in the state that provides the highest utility, taking into account his or her location preference type $s$.

In the third and final stage, the government of each state $i$ selects the tax rate $t_{i}^{L}$ to impose on labor agents. This tax rate is set to balance the state's budget given the commitment to the level of the public good $y_{i}$ made in stage 1 and given the tax revenue collected from the capital agents who have chosen to locate in state $i$.

A Nash equilibrium of this tax competition model is a set of strategies $\left(y_{1}, t_{1}^{c}\right)$ and $\left(y_{2}, t_{2}^{C}\right)$ such that $\left(y_{1}, t_{1}^{C}\right)$ maximizes the utility of labor agents in state 1 taking as given the offer $\left(y_{2}, t_{2}^{c}\right)$ by state 2 , and $\left(y_{2}, t_{2}^{c}\right)$ maximizes the utility of labor agents in state 2 taking as given the offer $\left(y_{1}, t_{1}^{c}\right)$ by state 1 .

Note that while I am calling this the uniform taxation regime, the tax rate $t_{i}$ on capital agents will in general be different from the tax rate $t_{i}^{t}$ on labor agents. By uniform, I mean uniform across all capital agents only. This is distinguished from the discriminatory taxation regime, in which a state government offers different tax rates to different capital agents.

\section{Equilibrium}

Now let's examine the second stage of the game: how the capital agents choose between the two locations taking as given the packages $\left(y_{i}, t_{i}^{c}\right)$ offered at each location.

Start by defining an agent's utility, $v^{*}(y, t)$, as

(2) $\quad v^{*}(y, t)=\max _{x}(1-t) x+u(y)+g(1-x)$. 
This is maximized utility conditioned upon locating in a state with public good $y$ and tax rate $t$ excluding the switching cost $s$. It is straightforward to see that a capital agent's location decision follows a cutoff rule:

$$
s\left(y_{1}, t_{1}^{C}, y_{2}, t_{2}^{c}\right)=v^{*}\left(y_{2}, t_{2}^{C}\right)-v^{*}\left(y_{1}, t_{1}^{C}\right)
$$

If a capital agent's $s$ exceeds $s$, state 1 is optimal; otherwise, state 2 is optimal. To see this, suppose that $s>0$. This means that the value of the package offered in state $2, v_{2}^{*} \equiv v^{*}\left(y_{2}, t_{2}^{\mathcal{C}}\right)$, exceeds the value of the package offered in state $1, v_{1}^{*}$ $v^{*}\left(y_{1}, t_{1}^{C}\right)$. Hence all capital agents with a preference for state 2 , that is, all those with $s<0$, choose to locate in state 2 . Furthermore, agents with small positive $s<s$ will locate in state 2 because the difference in the value of the package in state 2 relative to that in state $1, s=v_{2}^{*}-v_{1}^{*}$, exceeds the cost of switching. For $s>s$, the cost of switching exceeds the difference in the values of the packages, and such agents locate in state 1 . The total number of capital agents who choose to locate in state 1 as a function of the packages offered in the two states is

$$
q_{1}^{C}\left(y_{1}, t_{1}^{C}, y_{2}, t_{2}^{C}\right)=(1-\alpha) 2 N\left[1-F\left(s\left(y_{1}, t_{1}^{C}, y_{2}, t_{2}^{C}\right)\right]\right.
$$

This follows because the total population of capital agents is $(1-\alpha) 2 N$, and a fraction $1-F(s)$ have $s>s$, so they locate in state 1 .

Before going any further, I must determine the relationship between the tax rate an agent faces and the level of the private good the agent produces. At a tax rate of $t$, a capital agent selects a production level of $x$ to solve problem (2). The firstorder condition of this problem is

$$
(1-t)-g^{\prime}(1-x)=0 .
$$


Let $x(t)$ be an agent's optimal choice of a production level $x$ when the agent faces a tax rate $t$. Note that the relationship between production and the tax rate $t$ is the same for capital agents and labor agents since they have the same preferences and use the same technology.

For each state government, taxes on labor agents finance the difference between the total expenditure on the public good and the amount of tax revenues collected from capital agents. The tax rate $t_{1}^{L}\left(y_{1}, t_{1}^{c}, y_{2}, t_{2}^{c}\right)$ on labor agents in state 1 must, then, satisfy

$$
t_{1}^{L} \cdot x\left(t_{1}^{L}\right) \cdot \alpha N=y_{1}-\left[t_{1}^{C} \cdot x^{C}\left(t_{1}^{C}\right) \cdot q_{1}^{\mathcal{C}}\left(y_{1}, t_{1}^{C}, y_{2}, t_{2}^{C}\right)\right]
$$

The left side of $(6)$ is the total tax revenue collected from labor agents in state 1. Each agent pays $t_{1}^{L} \cdot x\left(t_{1}^{L}\right)$, and there are $\alpha N$ such agents. The right side of $(6)$ is the difference between the total amount of public good that is to be provided by state 1 and the total tax revenue collected from capital agents who locate in state 1.

Now I can specify the payoff to labor agents in state 1 as a function of the packages $\left(y_{1}, t_{1}^{\odot}\right)$ and $\left(y_{2}, t_{2}^{C}\right)$ offered in each state. This payoff is

$$
\begin{gathered}
v_{1}^{L}\left(y_{1}, t_{1}^{C}, y_{2}, t_{2}^{C}\right)=[1 \\
\left.-t_{1}^{L}\left(y_{1}, t_{1}^{C}, y_{2}, t_{2}^{C}\right)\right) \cdot x\left(t_{1}^{L}\left(y_{1}, t_{1}^{C}, y_{2}, t_{2}^{C}\right)\right]+u\left(y_{1}\right) \\
+g\left(1-x\left(t_{1}^{L}\left(y_{1}, t_{1}^{C}, y_{2}, t_{2}^{C}\right)\right)\right) .
\end{gathered}
$$

The payoff to labor agents in state 2 is calculated in a similar fashion. I can now use this formal notation to restate the definition of equilibrium. It is a set of packages $\left(y_{1}, \tilde{I}_{1}\right)$ and $\left(\bar{y}_{2}, \tilde{l}_{2}\right)$ such that $\left(\ddot{y}_{1}, \tilde{I}_{1}^{C}\right)$ is the solution to

$$
\max _{\left(y_{1}, r_{1}\right.} v_{1}^{L}\left(y_{1}, t_{1}^{C}, y_{2}, z_{2}^{C}\right)
$$

and $\left(y_{2}, F_{2}^{C}\right)$ is the solution to the analogous condition. 
The Status Quo: Discriminatory Taxation

Now I turn to the status quo, or the discriminatory taxation regime. Here state governments can observe some characteristics of the capital agents and can legally use the tax system to discriminate based on those differences. What I am trying to capture here is the current practice of state governments giving tax breaks to firms that might locate elsewhere, in order to attract these firms to their state.

\section{In-State ys. Out-State}

I assume that states can observe a single characteristic about a capital agent and that the characteristic can take on one of two values, $A$ or $B$. The significance of this characteristic is that it indicates something about $s$, the location preference parameter of the agent. In particular, type $A$ capital agents tend to prefer state 1 , while type $B$ capital agents tend to prefer state 2 . Note that although this characteristic provides some information about $s$, the information is nonetheless imperfect. In particular, despite the general tendency, some type $A$ agents may strongly prefer state 2 , and some type $B$ agents may strongly prefer state 1 .

Before I delve further into the formal discussion, let me tell a story that illustrates what I am trying to capture here. Suppose a firm already has a plant in state 1 and is considering building a new plant to produce a related product. The preferable location for the new plant may be state 2 because of the need for access to a particular input. However, the preferable location for the new plant is more likely to be state 1 . This follows because the chance that the particular input is available is equal in the two states, and economies of scope might be achieved by operating the plant near the companion plant that is already in state 1 . This firm can 
thus be classified as a type $A$ agent. Such an agent is likely to prefer state 1 , but there is some possibility that the agent prefers state 2 .

To be formal about this, assume that half of all the capital agents are type $A$ and the other half are type $B$. Recall that $F(s)$ is the distribution of $s$ for the entire population of both types of capital agents and that $F(0)=1 / 2$; that is, half of all the capital agents have $s>0$ (so they prefer state 1), and half have $s<0$ (so they prefer state 2). Let $F^{\prime}(s)$ be the distribution of $s$ for type $j$, where $j=A, B$. Assume that $F^{A}(s)=1-F^{B}(-s)$. This is a symmetry assumption. It says that the fraction of the type $A$ population with location preference below some $s$ is the same as the fraction of the type $B$ population with location preference above $-s$. Assume further that $F^{A}(s) \leq F^{B}(s)$. This says that type $A$ agents are more likely to have high $s$ (and therefore prefer state 1 over 2 ) than type $B$ agents. In particular, it implies that $F^{A}(0)$ $\leq 1 / 2$ (so that at least half the type $A$ agents prefer state 1 ) and that $F^{B}(0) \geq 1 / 2$ (so that at least half the type $B$ agents prefer state 2). I will sometimes call type $A$ agents likely in-state agents for state 1 and likely out-state agents for state 2. Analogously, type $B$ agents will be called likely in-state agents for state 2 and likely out-state agents for state 1 .

\section{Equilibrium}

State governments can practice tax discrimination if offering types, or groups, of agents different tax rates is feasible. By feasible here, I mean that the state governments are legally permitted to do this. (They are not blocked by any federal law.) I aIso mean that the governments have the necessary information to do it. (A member of the likely in-state group cannot mimic membership in the likely out-state group in order to obtain a favorable tax rate.) 
Under the discriminatory taxation regime, tax competition between two state governments proceeds as follows. The government of each state $i$ selects a public good level $y_{i}$ and tax rates $t_{i}^{A}$ and $t_{i}^{B}$ for groups of agents $A$ and $B$. State 1 's government takes the behavior $\left(y, t_{2}^{A}, t_{2}^{B}\right)$ of state 2 as given and chooses $\left(y, t_{1}^{A}, t_{1}^{B}\right)$ to maximize the utility of the labor agents in state 1. Similarly, state 2's government takes $\left(y, t_{1}^{1}, t_{1}^{B}\right)$ as given and chooses $\left(y, t_{2}^{A}, t_{2}^{B}\right)$ to maximize the utility of the labor agents in state 2. The equilibrium of tax competition is the Nash equilibrium of this game. In a symmetric equilibrium with discriminatory taxation, the tax rate that state 1 's government offers to its likely in-state agents (group $A$ ) is the same as the tax rate offered by state 2 to its likely in-state agents (group $B$ ); that is, $t_{1}^{A}=t_{2}^{B}=t^{i n}$, and $t_{1}^{B}=t_{2}^{A}=t^{\text {out }}$

\section{Comparing the Regimes}

Now I will compare the discriminatory taxation regime with the uniform taxation regime. I begin by discussing the results for a particular numerical example. I then discuss which results hold for more general parameters.

An Example

Suppose that the components of the utility function are quadratic:

(9) $\quad u(y)=2 y-\left(y^{2} / 2\right)$

(10) $g(1-x)=-\left(x^{2} / 2\right)$

Suppose that the range of $s$ is the interval $[-0.1,0.1]$ and that the density function for location preference type $s$ for agent group $A$ is

(11) $f^{\prime}(s)=5+50 s$ 
for $s \in[-0.1,0.1]$. Analogously, the density function for the distribution of $s$ for agent group $B$ is

$$
f^{B}(s)=5-50 s
$$

for $s \in[-0.1,0.1]$. The distribution is skewed toward positive $s$ in group $A$ and toward negative $s$ in group $B$. That is, agents in group $A$ tend to prefer state 1 , and agents in group $B$ tend to prefer state 2 . The density of both groups combined is the uniform density:

$$
f(s)=(1 / 2) f^{A}(s)+(1 / 2) f^{B}(s)=5
$$

for $s \in[-0.1,0.1]$.

To complete the description of the model economy, assume that $N=1$ and $\alpha=0.75$. With $\alpha=0.75$, labor agents constitute 75 percent of the total population.)

I now compare the equilibria in the economy under the two policy regimes. The accompanying table displays the equilibrium values I computed for this example under each regime.

I begin my discussion with the uniform taxation regime. Let me first note that in solving for equilibrium in this case, I plotted the reaction functions for the two states, and I was able to show that there is a unique pure-strategy equilibrium of the tax competition game. This unique equilibrium is symmetric; in it, both states offer the same public good levels and the same tax rates to capital agents: $y_{1}=y_{2}$, and $\nexists_{1}^{c}=\not_{2}^{c}$

Recall that in the uniform taxation regime, the tax rate offered to likely instate capital agents must equal the tax rate offered to likely out-state agents. In the 
example, as the table shows, the equilibrium level of these tax rates is 0.099 . Note that the tax rate faced by capital agents is much lower than the 0.358 faced by labor agents. The competition across the two states to attract capital drives the tax to capital agents down to a relatively low level. Labor agents thus bear a disproportionate share of the cost of the public good.

The table aIso shows the equilibrium values in the discriminatory tax regime. ${ }^{2}$ When discrimination is feasible, the tax rate offered to out-state capital agents is only 0.063 compared with the rate of 0.099 that all capital agents pay with uniform taxation. This is not surprising. From the vantage point of state 1 , the majority of agents in its out-state group $(B)$ prefer to locate in state 2 . In order to attract these out-state agents, the local government must tempt them with a low tax rate.

A surprising result in the table is that the equilibrium tax rate to likely in-state agents is actually lower with discriminatory taxation than with uniform taxation $(0.093$ vs. 0.099$)$. To see why this is surprising, note that a state has greater bargaining power over its in-state agents than its out-state agents. We might think that to exploit this bargaining power, a state would set a higher tax rate when it can target this rate specifically at in-state agents compared to the rate it would set when the tax also applies to likely out-state agents. While this is true, another effect goes the other way. A likely in-state agent of state 1 is a likely out-state agent of state 2 . State 2 offers such an agent a great tax deal (a rate of 0.063 ). This is such a low rate that state 1 is forced to respond by offering a tax rate lower than the rate the agent pays with uniform taxation.

In equilibrium, total tax revenue from capital in less in the điscriminatory taxation regime than in the uniform taxation regime. In the discriminatory regime, 
the burden of paying for the public good falls more heavily on the labor agents. Their tax rate equals 0.362 compared to the level of 0.358 in the uniform regime. The level of public good provision in the discriminatory regime is lower than the level in the uniform regime (0.192 vs. 0.195$)$.

Now consider the welfare of the various parties in the two regimes. Recall that $v$ denotes utility excluding any switching cost $|s|$ that is incurred. In the uniform taxation regime, all capital agents are offered $v=0.777$ by both states. Agents with positive $s$ locate in state 1 , and agents with negative $s$ locate in state 2 , so no switching disutility $s$ is incurred by any agent. In the discriminatory taxation regime, agents in group $A$ are offered 0.777 in state 1 and 0.804 in state 2 . For agents with $s>0.804-0.777=s^{4}$, the cost of switching to state 2 exceeds the benefit of the special tax deal offered by state 2 . So these agents all locate in state 1 . Their utility of 0.777 is virtually the same as in the uniform taxation regime. (Actually it is slightly higher when evaluated at additional decimal points.) Agents with positive $s$ less than $s^{4}$ all switch to state 2 since the benefit of out-state tax treatment exceeds the switching cost. Agents in group $A$ with negative $s(25$ percent of group $A$ ) all prefer state 2 , so they enjoy the special tax deal of state 2 without having to suffer any disutility of switching. In summary, all agents in group $A$ are better off with discrimination than with uniform taxation for capital agents. Analogously, all group $B$ members are better off. However, the welfare of labor agents is lower in the discriminatory taxation regime because there labor agents pay higher taxes and enjoy less of the public good.

The average utility of all the agents in the economy, both capital and labor, is also shown in the table. (Note that in computing this average, the weight of each 
kind of agent is equal to the weight of each kind in the population.) Average utility is greater with uniform taxation than with discriminatory taxation. This, of course, does not mean that the uniform regime is better than the discriminatory regime, since the two regimes cannot be Pareto-ranked. Suppose, however, that another period were introduced into the model, a period before the action discussed so far. In this initial period, agents do not yet know whether they will turn out be labor agents or type $A$ capital agents or type $B$ capital agents. All agents in the economy are identical at this point in terms of the distribution of the various outcomes. The average utility figures reported in the table equal the ex ante expected utility of each agent. The figures show that, ex ante, all individuals in the economy are better off in the uniform taxation regime.

This result has two explanations. One has to do with where the capital agents locate. In the discriminatory taxation regime, some agents locate in their lesspreferreà state, from the perspective of their location preference parameter $s$. Agents in group $A$ with $s$ between 0 and $s^{s}$ all prefer state 1 , but are induced to locate in state 2 because they qualify for the likely out-state tax rate in state 2 while they must pay the higher likely in-state tax rate in state 1. Define the aggregate switching cost to be the total amount of switching costs that are incurred in the economy; that is,

$$
S=N(1-\alpha) \int_{0}^{\mu} f^{A}(s) s d s .
$$

(Note that the $N(1-\alpha)$ term is just the total number of capital agents and that this formula is simplified because of the symmetry between $f^{A}$ and $f^{B}$.) In the discriminatory taxation regime, the aggregate switching cost equals 0.002 . Not so in the uniform taxation regime. There each capital agent faces the same tax of 0.099 no 
matter where the agent locates. Hence taxes play no role in the location decision; the most efficient location is selected. In the uniform taxation regime, therefore, the aggregate switching cost is zero.

The other explanation for higher average utility in the uniform taxation regime has to do with the distortions from taxes. Recall that $v^{*}(y, t)$, defined by $(2)$, is an agent's maximized utility in units of the consumption good; taken as given are the public good level $y$ and the tax rate $t$. It is straightforward to show that the sum of utility in consumption units plus tax revenue, $v^{*}(y, t)+t \times(t)$, strictly decreases in $t$. (The deadweight loss is greater the higher the tax.) Moreover, this sum decreases at an increasing rate; that is, it is concave in $t$. In other words, the deadweight loss increases more than proportionally with an increase in the tax burden on an agent. This implies that for a given amount of tax revenue collected, the deadweight loss is minimized by taxing all agents at the same rate. Now consider a movement from the discriminatory taxation regime to the uniform taxation regime. This makes the tax burden more equal among capital agents-and across labor and capital agents. The greater uniformity of tax rates tends to reduce the deadweight loss from taxation and so to raise average utility.

I can now explain why the public good level is higher in the uniform taxation regime. The greater equality of the tax burden reduces the marginal social cost of collecting one more unit of the consumption good in taxes. The government of state $i$ chooses the public good level so that the social marginal benefit equals the social marginal cost. Since the social marginal cost is lower in the uniform taxation regime, the optimal public good level is higher. Equating social marginal benefit with social marginal cost might be confusing here, since the objective of a state government is 
to maximize the utility of only the labor agents within the state. However, the utility of capital agents for the public good also enters into the determination of the optimal public good because it affects how many capital agents move to the state.

\section{Beyond the Example}

The discussion so far has revolved around a single numerical example. Now let's see what happens for more general parameters.

The functional forms are the same as in the example. In particular, utilities of the public good and leisure are quadratic as in (9) and (10), and the densities of $s$ in groups $A$ and $B$ are linear as in (11) and (12). For this discussion, I will assume that a symmetric equilibrium exists in both taxation regimes, as is true for the numerical example.

I have compared the symmetric equilibria of the two regimes. This proved to be hard to do analytically. So, instead, I used a computer to comprehensively scan the parameter space. Using this computer-aided procedure, I obtained the following results.

RESULT 1. Total tax revenue collected from capital agents is higher in the uniform taxation regime than in the discriminatory taxation regime.

This result says that adoption of the Burstein-Rolnick policy increases the tax revenue from capital.

RESULT 2. If, in both taxation regimes, the equilibrium tax rates faced by all capital agents are lower than the rates faced by labor agents, then the level of the public good is higher in the uniform taxation regime and so is average utility. 
This result assumes that competition over capital agents is sufficiently great that tax rates are lower on capital agents than on labor agents. That is actually an assumption about the distribution of the location preference parameter $s$ among the capital agents, namely, that the average value of $|s|$ is relatively Iow. If so, capital agents will tend to be responsive to small differences in tax rates between the two states, and the competition between the states will drive the tax rate on capital to relatively low levels. This is a reasonable case to focus on, since a starting point of the model is the assumption that capital is mobile.

What happens if the average value of $|s|$ is high, so that capital agents on average regard the two locations as poor substitutes? Since the state governments maximize the welfare of the labor agents, they will set high tax rates on capital in order to exploit the fact that the location decisions of capital agents are relatively insensitive to differences in tax rates across states. Then the tax rates on labor will be relatively low or even negative. (A negative tax rate on labor means the high taxes on capital are funding subsidies to labor agents.) According to Result 1, the equilibrium tax revenue from capital is higher with uniform taxation than with discriminatory taxation. However, Result 2 does not apply here because the condition for the result that the tax rates on capital be lower than the rates on labor does not hold here.

I have found parameter values that do not satisfy the tradition of Result 2 , under which average utility is lower with uniform taxation than with discriminatory taxation. That is, there exist parameters for the economy under which adopting the Burstein-Rolnick policy reduces average welfare. In such a situation, under the status quo, discriminatory taxation regime, capital agents are already bearing a disproportionate share of the tax burden. Adopting the Burstein-Rolnick policy then enables 
state governments to squeeze even more out of capital agents. The higher taxes on capital agents increase the deadweight loss incurred through them. Furthermore, if adoption of the policy leads to increased subsidies to labor agents, then the deadweight loss incurred through labor agents increases as well.

\section{Concluding Remarks}

The use of discriminatory tax breaks by state governments to attract businesses has generated a great deal of controversy. Burstein and Rolnick (1995) have proposed that it be banned, that each state government be required by federal law to treat all the capital that locates within its state in the same way. This article presents a formal model in which adoption of this policy can increase aggregate welfare. In the model, states compete to attract capital whether or not the policy is adopted. But if the policy is adopted, it changes the dimensions under which states compete. Under the functional forms and parameter values considered here, the policy has three effects. It increases the total tax revenue collected from capital agents, which is used to finance an increase in public good spending. It results in a more efficient configuration of plant locations. And it reduces the deadweight loss of taxation per dollar collected by making the distribution of the tax burden more equal.

These results are all obtained in a model with simple functional forms. I make no claim of generality for the results. Rather, my purpose is to illustrate potential benefits of the policy and to highlight the channels through which these potential benefits might be realized. Certainly, for other specifications of the model, opposite results can be achieved. For example, as noted earlier, if the parameters are such that capital is relatively immobile, so that in equilibrium it is taxed at a relatively high rate, then for certain parameters, adoption of the policy can reduce aggregate 
welfare. Specifying a model structure under which adoption of the policy can reduce the equilibrium tax revenue from capital is also fairly easy. ${ }^{3}$

My analysis leaves out some possibly relevant factors. For example, it does not consider the possibility that the choice between the discriminatory and uniform taxation regimes may affect the ability of state governments to sustain collusive agreements not to compete. Work in the industrial organization literature sometimes argues that having the ability to price-discriminate can undermine oligopolistic discipline in sustaining collusion. (See Scherer and Ross 1990.) Espinosa (1992) presents a formal model related to this issue.

My model also leaves out possible negative effects of government actions. In my model, the competition between states for capital drives the tax rate on capital to a relatively low level, and as a result, the level of public good provision is lower than it would be without this competition. The increase in public spending that can result from the policy can be a good thing here. This result requires a benign view of government actions. If we take a negative view of government-say, one in which government spending represents transfers to government bureaucrats (with lots of deadweight loss)-then we would probably not regard any increase in the ability to extract tax revenue from capital as a favorable effect of the policy. McLure (1986) makes the point that to the extent that government is a Leviathan, policies that impede competition across states might not be desirable.

In my model, agents are identical in most respects, and the social pie is maximized by having all agents in the economy pay the same tax rate. This puts a uniform taxation rule on a good footing from the start. However, in a world with heterogeneous agents, a government may find some advantages to having different 
agents pay different taxes, apart from any effect this policy might have on competition across states for capital. In other words, a uniform taxation requirement may impede a government attempting to set up some optimal tax structure.

The reason states compete for capital in my model is to enlarge their own tax base, that is, to increase the number of agents over which the fixed cost of the public good is spread. Another reason states might compete for capital is to acquire businesses that might provide some kind of externality to the state that is not internalized by the market price for the factor. Suppose, for example, that high-tech industries or sport teams are thought to provide some sort of external benefit to a state. Then state governments might offer tax breaks or even subsidies to these industries but not to other industries like dry cleaning. These tax breaks and subsidies may be beneficial to the extent that they increase the total amount of activity in the benefiting industries at the national level (as opposed to simply affecting the location choices of a fixed amount of these activities). To the extent that is true, banning tax discrimination by states might reduce aggregate welfare. 


\section{Notes}

*The author is grateful to Hal Cole, Patrick Kehoe, and Warren Weber for helpful comments and to Kathy Rolfe for editorial assistance.

${ }^{1}$ See, for example, the discussion in Schweke, Rist, and Dabson 1994, p. 70, on regional collaboration. For an argument that states might actually be worse off if they could feasibly cooperate, see Kehoe 1989.

${ }^{2}$ I obtained the discriminatory equilibrium by numerically solving the symmetric first-order conditions of the state government's problem. I verified that the reported strategies are a globally optimal response; hence it is an equilibrium. I did not verify that this is a unique equilibrium. Recall that I did verify uniqueness for the uniform taxation regime. But in that case, plotting the reaction functions to construct the equilibrium set was relatively easy. Here it is relatively difficult.

It is important, of course, for equilibrium to be unique in each regime when making a comparative statics claim. Fortunately, I can say something about uniqueness in the discriminatory taxation regime. Suppose the density function in group $A$ is given by $f^{A}(s)=5+\xi s$ (in the numerical example, $\xi=50$ ). The discriminatory regime collapses to the uniform taxation regime as the parameter $\xi$ goes to zero. By a continuity argument, the equilibrium in the discriminatory regime is unique for $\xi$ close enough to zero. Results 1 and 2 reported later apply for general parameters of this linear economy, including the case of $\xi$ close to zero.

${ }^{3}$ The model of this article has two different types of capital agents: type $A$ and type $B$. Each of these groups has an asymmetry in the distribution of location preference for the two states. In particular, the group that state 1 would like to tax 
at a relatively high rate is the same group that state 2 would like to tax at a relatively low rate. That is, state 1 's likely in-state group is state 2 's likely out-state group. Imagine an alternative model in which for each group the distribution of location preferences is symmetric. However, suppose the mean value of $|s|$ is greater in group $A$ than in group $B$. In that kind of model, both states will desire to tax group $A$ at a relatively high rate since on average these agents find the states to be poor substitutes. Both states will desire to $\operatorname{tax}$ group $B$ at a relatively low rate. For this kind of model, finding parameter values under which the Burstein-Rolnick policy to ban tax breaks reduces equitibrium tax revenue from capital is easy. This kind of structure is discussed in Borenstein 1985 and Holmes 1989 in the context of price discrimination. 


\section{References}

Borenstein, Severin. 1985. Price discrimination in free-entry markets. Rand Journal of Economics 16 (Autumn): 380-97.

Burstein, Melvin L., and Rolnick, Arthur J. 1995. Congress should end the economic war among the states. The Region 9 (March): 2-20. Special Issue: Federal Reserve Bank of Minneapolis 1994 Annual Report.

Espinosa, Maria Paz. 1992. Delivered pricing, FOB pricing, and collusion in spatial market. Rand Journal of Economics 23 (Spring): 64-85.

Holmes, Thomas J. 1989. The effects of third-degree price discrimination in oligopo1y. American Economic Review 79 (March): 244-50.

Kehoe, Patrick J. 1989. Policy cooperation among benevolent governments may be undesirable. Review of Economic Studies 56 (April): 289-96.

McLure, Charles E. 1986. Tax competition: Is what's good for the private goose also good for the public gander? National Tax Journal 39 (September): 341-48.

Review and outlook: A governor's gimmick. 1995. Wall Street Journal, March 17: A10.

Scherer, F.M., and Ross, David. 1990. Industrial market structure and economic performance. Boston: Houghton Mifflin.

Schweke, William; Rist, Carl; and Dabson, Brian. 1994. Bidding for business: Are cities and states selling themselves short? Washington, D.C.: Corporation for Enterprise Development.

Wildasin, David E. 1991. Some rudimentary “duopolity" theory. Regional Science and Urban Economics 21 (November): 393-421. 
Wilson, John D. 1986. A theory of interregional tax competition. Journal of Urban Economics 19 (May): 296-315.

Zipser, Andy. 1995. Civil war, round two. Barron's, April 3: 23-26. 
Equilibrium in the Example Economy Under the Two Taxation Regimes

\begin{tabular}{lll}
\hline & \multicolumn{2}{l}{ Value of Variable When Texation Is } \\
\cline { 2 - 3 } Variable & Uniform & Discriminatory \\
\hline & & \\
Public Good Production & .195 & .192 \\
Tax Rates & & \\
Capital Agents & & .093 \\
In-State & .099 & .063 \\
Out-State & .099 & .362 \\
Labor Agents & .358 & \\
& & \\
Utility & & .777 \\
Capital Agents & & .804 \\
In-State & .777 & .569 \\
Out-State & .777 & .621 \\
Labor Agents & .576 & \\
\hline Average & .626 & \\
\hline
\end{tabular}

